\title{
E-Readiness Assessment Information System. A Case Study of Microfinance Institutions (MFIs) in Kenya
}

\author{
Dorothy Mwongeli Kalui \\ Department of Computer Science, Meru University of Science and Technology, Kenya
}

\begin{abstract}
Microfinance institutions provide lending facilities, money transfer and micro-insurance, among others, to the economically active poor, low-income households and micro and small scale enterprises in both rural and urban areas. However, digital financial service delivery channels and methodologies confront a number of challenges mainly the e-Readiness of both MFIs adopt modern and innovative information and communication technology and reduce or eliminate the digital divide. In terms of e-banking it is likely that some e-Readiness indicators are more revealing than others. At the same time, e- readiness indicators are not static; they are influenced by investments, policy, and a multitude of circumstantial socio-economic factors. In this paper, we meet these challenges and propose a generic assessment information system that can be used to assess the e-Readiness of MFIs in Kenya. With validation and a full blown practical implementation on sample MFIs, we demonstrate our system's efficiency and scalability.
\end{abstract}

Keywords: Assessment, Information system, Kenya, e-banking, MFI, Clients

DOI: $10.7176 / \mathrm{IKM} / 9-2-04$

\section{Introduction}

Various findings show that utilization and ability to implement and use recent and state-of-the-art ICT (information and communication technology) and ICT enabled services is not uniform across the various financial service providers within a country and across countries (CBK, 2013; Chavan, 2013; Kumar, Nair, Parsons, \& Urdapilleta, 2006; Mulwa \& Waema, 2016; Ozuru, Chikwe, \& Uduma, 2010). This is due to difference in e-Readiness in ICT adoption, resource availability and technological expertise. For example, the Kenyan banking industry utilization of ICT is different subject to the size of the bank, ownership (whether local or foreign or multinational), type, resource base and access to technology (Mwongeli \& Christopher, 2015). Ebanking realizes greater level of customer contentment and retention if tailored to exact requirements of MFIs clients' base. In particular Kenya's MFIs have been spending in ICTs in their processes to achieve better level of e-Readiness for efficacy and efficiency services (Mwongeli, Moturi, \& Muketha, 2017). E-banking is the only way to stay connected to the customers at any place and any time. It results in high performance in the banking industry through faster delivery of information and services among the customers and service provider (Chavan, 2013; Mwongeli et al., 2017; Padaachi \& Seetanah, 2010).

E-Readiness has been defined as the degree in which a country, business enterprises, or community is prepared and capable to participate in the networked world in their degree of relative knowledge and preparedness in most of the essential areas for the acceptance and use of ICTs and ICT applications (CID, 2001). Authors in Mwongeli et al define e-readiness in relation to the MFIs as ability to adopt, use and benefit from ICT in the provision of financial services to their customers (Mwongeli \& Christopher, 2015).

A number of e-Readiness assessments have been proposed (APEC, 2000; CID, 2001; CSPP, 1998; McConnell, 2001; Peters, 2001) which were reviewed in our earlier work to develop a suitable framework IFA (integrated framework assessment) (Mwongeli \& Christopher, 2015). In this study we extend IFA framework by implementing using an information system.

Most of the existing e-readiness frameworks are E-economy readiness tools that focus on a nation's readiness and E-society readiness tools that measure the ability of the overall society. There are few frameworks for industry level and sector level (Aminali, Albadvi, \& Naude, 2009; Mwongeli \& Christopher, 2015). Moreover e-Readiness assessment in developing world has been studied in recent years by several researchers. However, studies focusing on MFIs in developing countries such as Kenya at industry and country level are few. In (Mwongeli \& Christopher, 2015) authors proposed e-Readiness assessment framework for Microfinance institutions dubbed IFA. The framework consists of two components namely categories and indicators. Category refers to domains while indicators are clusters in each category.It is related to the level of IT acquisition or adoption mainly e-commerce by MFIs. Microfinance institutions encounters challenges of e-Readiness assessment which affects MFIs improvement and monitoring progress of ICT strategy implementation.

The main objective of this study is to develop e-Readiness information system that focuses on financial industry for assessing the e-Readiness levels. This paper proposes an assessment information system for eReadiness of MFIs in Kenya. The proposed information system is validated with the analysis of data collected from Microfinance institutions and their clients in Kenya (Mwongeli \& Christopher, 2015; Mwongeli et al., 2017). Using categories and indicators proposed in our earlier studies Mwongeli \& Christopher 2015, 
information system was developed. It consists of four modules detailed in section 3 . The results inform of developed assessment information system are contained in section 4. The results are presented in tables and figures as shown in section 4.

The rest of this paper is organized as follows; Section 2 presents related works. Section 3 presents research methodology, Section 4 presents the proposed information system and finally Section 5 presents the conclusion.

\section{Related work}

Earlier studies in the area of e-banking, authors define e-banking as systems that facilitate MFIs customers to access accounts, conduct business or acquire information on financial products and services through a public or private network, the internet or mobile phone (Chavan, 2013; Mwongeli et al., 2017). The use of Automated Teller Machines (ATMs) is one example where a customer can access bank account by swapping a debit or ATM card in a machine and entering the PIN assigned to the customer by the bank. Internet banking or online banking can be termed as the service that lets consumers to execute banking transactions using a computer with an internet connection (Al-Fahim, 2012). M-banking allow customers to make banking transactions via a mobile phone connected to the internet.

\subsection{E-banking by Micro and Small scale Enterprises (MSES)}

The economy of most developing countries is cash driven with monetary transactions basically made through the exchange of bank notes and coins for goods and services. This trend is now giving way to up-to-date and sophisticated payment system where the currency and notes are converted to data, which are in turn conveyed through the telephone lines and satellite transponders. This is as a result of fast technological advancement and development in the financial sector (Gbadeyan \& Gbonda, 2011; Ozuru et al., 2010). There is faster distribution of information from the customer and service provider, thus distinguishing Internet enabled electronic banking system from the traditional banking system (Chavan, 2013; Padaachi \& Seetanah, 2010).

(Kumar et al., 2006) carried a study on correspondent banking in Brazil, where financial institutions operate commercial establishment using third party agents rather than their own branches. The primary focus is the third party to render services on behalf of the financial institution using modern and innovative technology such as Point of Sale (POS) devices. Correspondent banking was found to have permitted increased access to the unbanked, mainly the poor, profitably with risk sharing. Regulatory modifications were found to have prompted the growing popularity of correspondent banking mainly in the payments. The authors also found that the potential for duplication is high, with Prodem in Bolivia and Banco Azteca in Mexico having positively followed the Brazilian model with 30 and over 800 correspondent partnerships from gas stations to supermarkets in 2005 and 2002, respectively. The study recommend that the future of correspondent banking using suitable technology and innovations like the POS devices as in Brazil, Bolivia and Mexico are expected to continue to rise and be replicated across various countries. However authors point out the increased risks faced by financial institutions, their customers and retailers (agents) must not be overlooked.

(Walterfield \& Ramsing, 2004) in Moderation of a Virtual Conference by MicroSave emphasize that ebanking for the poor is influenced by technologically driven delivery channels and methodologies. (Susantya, Handayanib, \& Henrawanc, 2012) argues that commercialization solutions depend on other factors including skills and capabilities i.e., , the success of a small business or an SME can be connected to how well they manage their knowledge; e-Readiness to use and adapt to modern and innovative technology by the business and their real and prospective clients; access to ICT and ICT service providers and vendors, handling relationships with numerous implementing partners, literacy levels in society, and marketing and distribution approaches.

Several studies and literature including (Auta, 2010; Masocha, Chiliya, \& Zindiye, 2011) have recognized that mobile phone based solutions have unlimited potential particularly in emerging economy including Africa due to numerous factors such as: The African economy are not saturated with substitute payment and distribution channels e.g. ATMS, POS, branches and agency arrangements.; Mobile phone ownership and distribution is high, while automation and internet access is reasonably low especially at the low end market sectors (poor, lowincome households and MSEs). Poor infrastructural services such as roads, electricity and rail often make communication difficult; Cheque and electronic funds transfer usage are very low with low coverage.

According to (Makosana, 2014) the introduction of electronic banking present banking institutions a new aspect of opportunities and challenges. For instance, in Zimbabwe psychological issues including, compatibility, complexity, risk, convenience, security, privacy and cost were found to impact the adoption of electronic banking.

\subsection{Status of Microfinance in Kenya}

The Microfinance (Deposit Taking Institutions) Regulations 2008 define the legal, regulatory and supervisory framework for the microfinance industry in Kenya. The Microfinance Act became operational with effect from 2nd May 2008. It is, therefore, expected that the microfinance industry will play a crucial role in expanding 
financial markets and enhancing access to financial services and products by bulk of the Kenyans. According to Central Bank of Kenya report (CBK, 2013), only 10 MFIs are registered under the Act.

In Kenya, Safaricom and Airtel mobile phone providers launch of M-PESA and Zap money transfer services commenced and continue to pick momentum, thus confirming the potential of mobile telephony. There is a fast growth in the use of ICT and ICT enabled services in the provision of financial services ranging from operational processes to end user services thus decreasing drastically paper based process to paperless; to service delivery through ATMs, Electronic Funds Transfer (EFT), telephony such as M-PESA and zap money, internet and point of sale devices, among others. Existing studies (CBK, 2013; Mulwa \& Waema, 2016; Mwongeli \& Christopher, 2015) indicate that ICT has become a key element of most, if not all, financial institutions operations and service delivery. Additionally, networks the world over and pushes financial industry effectiveness and efficiency innovations and efforts. In order to increase market share and expand access, and keep in line with national and global trends and competition, financial institutions have incorporated ICT and ICT enabled services in their businesses $(\mathrm{CBK}, 2014)$. The poor perceive the growth of digital banking as key to offering new solutions to improve access to financial services (Chavan, 2013).

A study in Kenya found that agent phones and Point of service (POS) devices were used to deliver traditional banking services to users whose access method was their mobile phone or debit cards. There exists an association in operations among banks and mobile network operators whose undertakings are regulated by the Central Bank of Kenya and the Communications Authority of Kenya (Mulwa \& Waema, 2016).

Based on these issues, the literature concluded that ICT and ICT enabled services could therefore play a main role in the delivery of financial services to low income persons in specifically women who are mostly unbanked in Kenya.

Over the last few years a growing number of e-Readiness assessment systems with diverse underlying goal and meaning of e-Readiness have been developed. From one point of view in general each tool gauges how ready a society or economy is to gain from information technology and e-commerce. Therefore following this view e-Readiness assessment tools and models can be divided into two main types that are not mutually exclusive i.e. those ones that focus on basic infrastructure or a nation's readiness for business or economic growth, and those that focus on overall society to benefit from ICTs.

However, from other perspective whereas some tools gauge the readiness of countries and economies to use internet-technologies in a global platform, others are more concerned on assessing the readiness of particular industry sectors to adopt Internet technologies, e.g. VERDICT (Verify End User e-Readiness) tool and IFA. VERDICT was developed to measure e-Readiness of specific industry sectors to adopt internet technologies (Aminali et al., 2009; Ruikar, 2004). It measures the readiness level of organization to adapt and use e-commerce. The tool has four main dimensions: People, Process, Technology, and Management. VERDICT has a set of questions for each of these dimensions. In each question a statement is given. The statements and participants choose only one choice among six possible answer ones for each statement due to their agreement or disagreement with the statement. VERDICT relies on the judgment of the participants as to whether or not they agree with the statements in the context of their institution, department or work group. The responses from these questionnaires are transformed in scores under the broad dimensions of the areas measured. All four dimensions are considered significant for an institution to be e-ready. The scores are averaged and depending on the average score, the participants are presented with traffic light indicators, namely Red, Amber and Green to visually indicate their e-Readiness in each dimension as shown in Table 1.

Table 1: Guideline of Verdict's boundaries (staging)

\begin{tabular}{|l|l|}
\hline \multicolumn{1}{|c|}{ Range } & Traffic Light \\
\hline $3.5 \leq \mathrm{X} \leq 5$ & Green \\
\hline $2.5 \leq \mathrm{X}<3.5$ & Amber \\
\hline $0 \leq \mathrm{X}<2.5$ & \\
\hline
\end{tabular}

Red is an average score greater than or equal to zero and less than 2.5. Red indicates that several aspects within a dimension need critical attention to achieve e-Readiness. On the other hand, Amber is an average score greater than or equal to 2.5 and less than 3.5. Amber represent that several aspects within a dimension require attention to achieve e-readiness. While, Green is an average score greater than or equal to 3.5 and less than or equal to 5. Green indicates that the end-user organization has acceptable know-how and development in these aspects and therefore e-ready. The VERDICT was used in staging in a different industry and different categories.

The IFA e-Readiness is built on a concept borrowed from several existing e-Readiness assessment framework mentioned earlier in this paper and summarised in table 2. Authors used these e-Readiness 
frameworks to form the basis of identifying the categories and indicators for the e-Readiness assessment of the microfinance institutions. Earlier researchers pointed out there are no one correct method to use the Guide; each community should determine how the guide best addresses its own needs. For example, the original CID tool detailed 19 indicators. However, some of the indicators are not applicable for MFIs in the Kenyan context e.g., enhancing education with ICT and schools access to information and communication technologies. Besides removing some of the 19 indicators, we introduced three new indicators (e-banking, payments, ICT financing) and renamed two indicators. The MFIs is a sector in the banking industry, hence the two indicators in CID tool weren't applicable, and from the MFIs perspective policy strategy is mainly concerned with ICTenvironment. IFA shown in fig. 1 consists of four categories and 11 indicators arrived from analysis of participants' reposes to questions concerning the proposed categories and indicators. The categories and respective indictors are: Network Policy (NP) which deals with ICT environment such as policy strategy, business environment and resource availability, mainly economic factors. It consists of three indicators namely Institutional ICT Policy and Strategy, ICT Human Capacity and ICT Financing; Network access is circumstances related to enabling physical connectivity. Appropriate working and affordable communication networks are therefore essential conditions for the development of e-banking. It was divided into two Indicators i.e., infrastructure and Access to services; networked society category is about MFI and clients online presence and growth. It consists of three representative indicators namely Clients and MFIs, online, ICT in everyday life and ICT in the MFIs (work place); networked Economy concerns ICT enabled services in the provision of financial services and employment opportunities. The category has three representative indicators, namely, ICT Employment opportunities, Payments and e-banking.

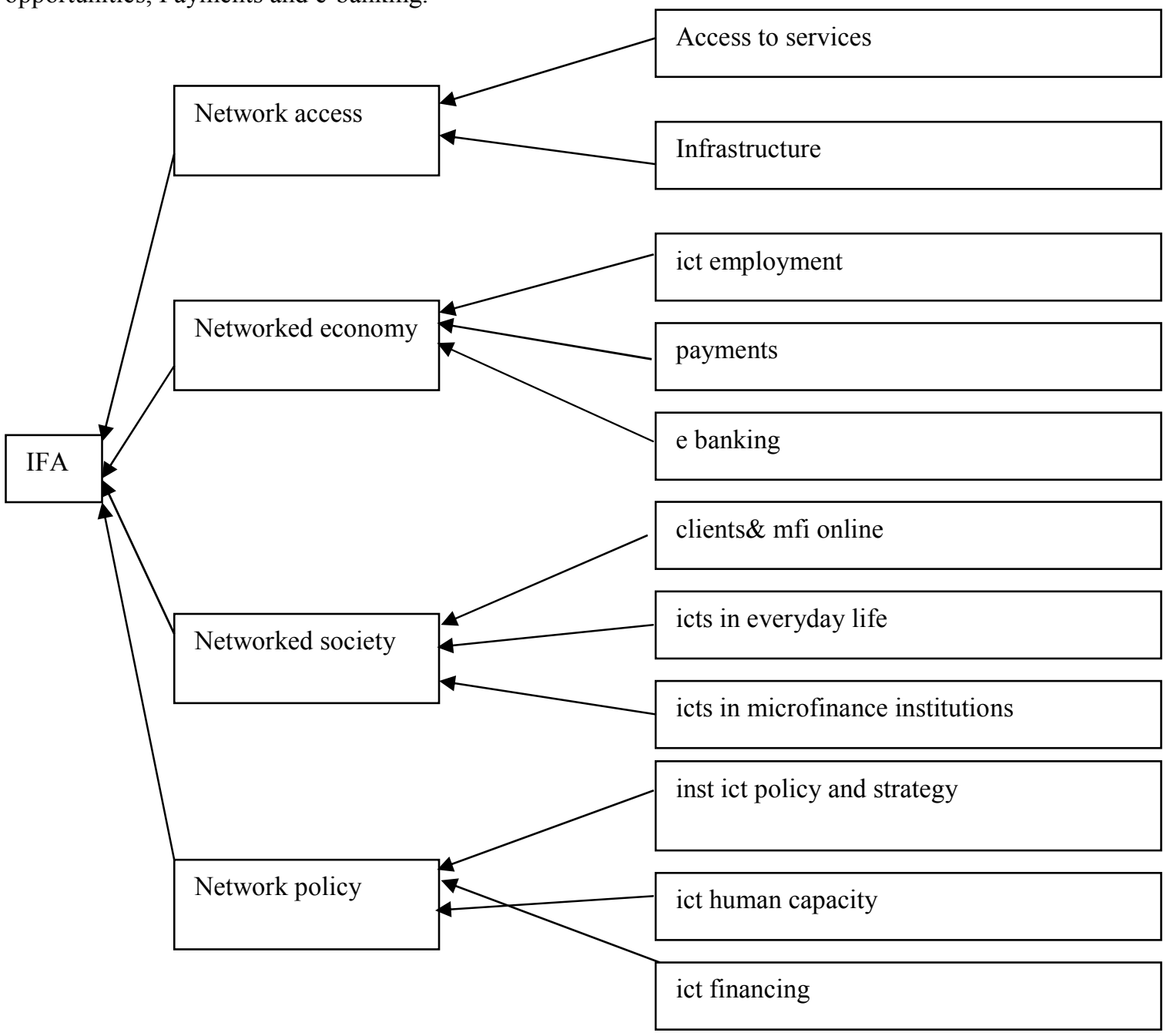

Figure 1. IFA adapted from (Mwongeli \& Christopher, 2015)

\section{Study Method}

The proposed assessment information system was based on integrated framework IFA (Mwongeli \& Christopher, 2015). In this paper we employ the basic idea of the work presented in VERDICT tool for staging. Here the MFI are offered with a list of statements and an assessment of their e-Readiness is established on their responses. To 
develop our proposed assessment information system data collection was mainly through questionnaires and secondary data was gathered from written reports, articles and especially from official and related websites of Microfinance Institutions. Table 2 indicate the reviewed framework and tools to extract relevant categories and indicators to our study.

Table 2. Summary of existing frameworks and tools used in the study

\begin{tabular}{|c|c|c|}
\hline CATEGORY & INDICATORS & TOOL/Framework \\
\hline \multirow[t]{2}{*}{ NETWOK ACCESS } & Infrastructure & $\begin{array}{l}\text { CSPP; CID; APEC; NRI; McConnel; Readiness for banking; } \\
\text { E-readiness for higher learning institutions; VERDICT }\end{array}$ \\
\hline & Access to Services & $\begin{array}{l}\text { CSPP; CID; Readiness for higher learning institutions; } \\
\text { Readiness for banking }\end{array}$ \\
\hline \multirow[t]{3}{*}{$\begin{array}{l}\text { NETWORKED } \\
\text { ECONOMY }\end{array}$} & $\begin{array}{l}\text { ICT employment } \\
\text { opportunities }\end{array}$ & $\begin{array}{l}\text { CID; Readiness for banking; NRI; APEC; Mc Connel; E- } \\
\text { readiness for higher learning institutions }\end{array}$ \\
\hline & Payments & Readiness for banking \\
\hline & E-banking & Readiness for banking; CID \\
\hline \multirow[t]{3}{*}{$\begin{array}{l}\text { NETWORK } \\
\text { POLICY }\end{array}$} & $\begin{array}{l}\text { Institutional ICT policy } \\
\& \text { strategy }\end{array}$ & $\begin{array}{l}\text { Readiness for banking; McConnell international report; } \\
\text { APEC; CID tool; NRI; E-Readiness of higher learning } \\
\text { institution }\end{array}$ \\
\hline & ICT Human Capacity & $\begin{array}{l}\text { VERDICT \& E-commerce; McConnell international report; } \\
\text { APEC; CID tool; NRI; E-Readiness of higher learning } \\
\text { institution }\end{array}$ \\
\hline & ICT financing & $\begin{array}{l}\text { E-Readiness of higher learning institution; McConnell } \\
\text { international report }\end{array}$ \\
\hline \multirow{3}{*}{$\begin{array}{l}\text { NETWORKED } \\
\text { SOCIETY }\end{array}$} & Clients \& MFIs online & CID tool; NRI report; E-Readiness of higher learning \\
\hline & ICT in everyday life & CID; NRI; E-Readiness of higher learning \\
\hline & $\begin{array}{l}\text { ICT } \\
\text { MFIs(workplace) }\end{array}$ & CID; NRI report; E-Readiness of higher learning \\
\hline
\end{tabular}

Adapted from (Mwongeli \& Christopher, 2015)

\subsection{Study Area and Respondents}

The work described in this paper was carried out in thirty leading Kenyan microfinance institutions between the years 2017 and 2018 .

The targeted population for this study was MFI Employees. Purposive sampling was used to identify key informants which include ICT managers, Customer care Managers and Chief executive officers. These are the people we felt they are well informed in MFI procedures, policies and customers experiences. A total of 90 respondents drawn from 30 MFIs participated in the study. The respondents (see Table 3) comprised of 30 CEOs one from each MFI, 30 top ICT managers one from each MFI and 30 customer care officers, each one from the participating MFIs. Table 3 shows the different categories of respondents who constituted the study sample

Table 3. Study sample

\begin{tabular}{|l|l|}
\hline Type of Respondents & Sample size \\
\hline ICT manager & 30 \\
\hline Customer care Managers & 30 \\
\hline Chief Executive & 30 \\
\hline Total & $\mathbf{9 0}$ \\
\hline
\end{tabular}

\subsection{The Instrument and Data Collection Tools}

In this study, a questionnaire was used as the main tools for data collection.

In order to understand the research area more and in detail, the necessary data must be collected (Kothari, 2008). Based on the nature of our research, we chose to collect data from both primary and secondary data sources. We collected primary data through questionnaires while secondary data in terms of documentation, by gathering information from written reports, articles and especially from official and related websites of participating MFIs. This complementary information was intended for describing the industry. The recommended questionnaires were piloted using a panel of experts and Chief Executive Officers (CEOs), general managers and top ICT managers of three selected MFIs. This internal discussion with various stakeholders was necessary to screen understandability of questionnaire for attainment the best result in designing e-readiness assessment information system. Screening internal consistency checked the reliability of responses. Ultimately after the changes were carried out, the data collection started. The calculated coefficient of Cronbach's Alpha $(\alpha)$ for whole questionnaire was $0.90(\alpha=0.90)$ that proved strongly the reliability of the questionnaire. A value $(\alpha)$ greater than $0.5(\alpha>0.5)$ is acceptable (Cronbach, 1951). Therefore, our questionnaire had sufficient reliability as a data 
collection tool.

Each of this respondents was issued with a five 5 scale Likert type questionnaire comprising of thirteen (13) indicator statements with a least score of 1 being strongly disagree and the highest score of 5 being strongly agree. They were required to fill online questionnaires with statements that have five choices to select one based on the current situation/judgement of the MFI. The questions are thirteen in total covering all the indicators in each category. Due to VERDICT method the least score that can be obtained for each category equals zero where the participant don't know the answers to any of the questions and therefore no e-readiness is realized for the category as well indicators. The highest score that can be deduced for each category and also indicator to imply an ideal e readiness equals 5 where the participants strongly agree with all the questions related to that category or indicator. The choice of obtaining scores for each category and indicator is based on average scores of responses.

\subsection{Data Analysis}

The selected MFIs employees were given questionnaires to fill. Out of 90 respondents targeted in this study, all $(100 \%)$ completed and returned it.

Statistical analysis software SPSS was used to analyze the data. The data analyses started with qualitative data gathered through questionnaires, being organized into relevant themes and concepts, and then interpreted by use of descriptive narrations. Statistical analyses Pearson correlation and factor analyses were used to identify significant categories and grouping indicators for each category. Correlation coefficients range from -1.0 to +1.0 indicates the strength and direction of a linear relationship between two or more random variables. The closer the coefficient is to 1.0 , whether it is negative or positive, the stronger the relationship. In general, correlations of 0.1 to 0.3 are considered small, 0.3 to 0.7 are considered significant while those above 0.7 are considered large (Geoffrey R. Marczyk, David DeMatteo, 2005).

Factor Analysis is a statistical approach that can be used to analyze interrelationship among a large number ofvariable and explain these variables and in terms of their common underlying dimensions (factors). The statistical approach involves finding a way of condensing the information contained in a number of original variables into smaller set of factors with minimum loss of information. We performed significant test for each of this variables / categories to check the value in the column significant in table 4. This indicates whether this variable is making statistically significant unique contribution to the equation. If the significant value (p) is less than .05 the variable is making a significant unique contributions to the prediction of the dependent variable (Pallat, 2003).

Table 4: Regression Analysis Results

\begin{tabular}{|l|l|l|}
\hline Category & Indicator & P VALUE(p) \\
\hline Network access & Access to services & 0.012 \\
& Infrastructure & 0.000 \\
\hline Network Policy & policy \&strategy, & 0.000 \\
& human capacity, & 0.005 \\
& financing & 0.08 \\
\hline Network Society & Clients \& Microfinance & 0.282 \\
& Institutions online & \\
& ICT in daily life & 0.020 \\
& ICT in Microfinance Institutions & 0.002 \\
& work place & \\
\hline Network economy & Employment opportunity & 0.001 \\
& Payments & 0.002 \\
& E-banking & 0.316 \\
\hline
\end{tabular}

Adapted from (Mwongeli \& Christopher, 2015)

\subsection{Results}

In this chapter we present our proposed information system using several diagrams and user manual from figures 6 to 21 .

\subsection{MFI e-Readiness assessment system}

The developed MFI e-Readiness assessment information system is designed to be used online. It is developed on the apache web server, mysql database using php, java script and html as the programming languages. Any MFI that has access to the internet would then be able to access this assessment system and carry out an assessment of their current state of readiness. A minimum of five persons in each assessment are required to publish the results. For a new MFI user, the first step will be to register. Once registered, an account is created for the MFI such in future the MFI will login using the username and password initially used. 
The information system has been designed to be easy to use, navigable, readable and with simple English.Previous states of readiness are stored in the database in the account of the particular MFI hence an MFI can evaluate itself at regular intervals using the previous assessment as baseline information hence assess whether they have improved within the duration under consideration. In the end the developed information system architecture is illustrated in fig.2. It consists of four modules namely input, computation, output and storage/database.

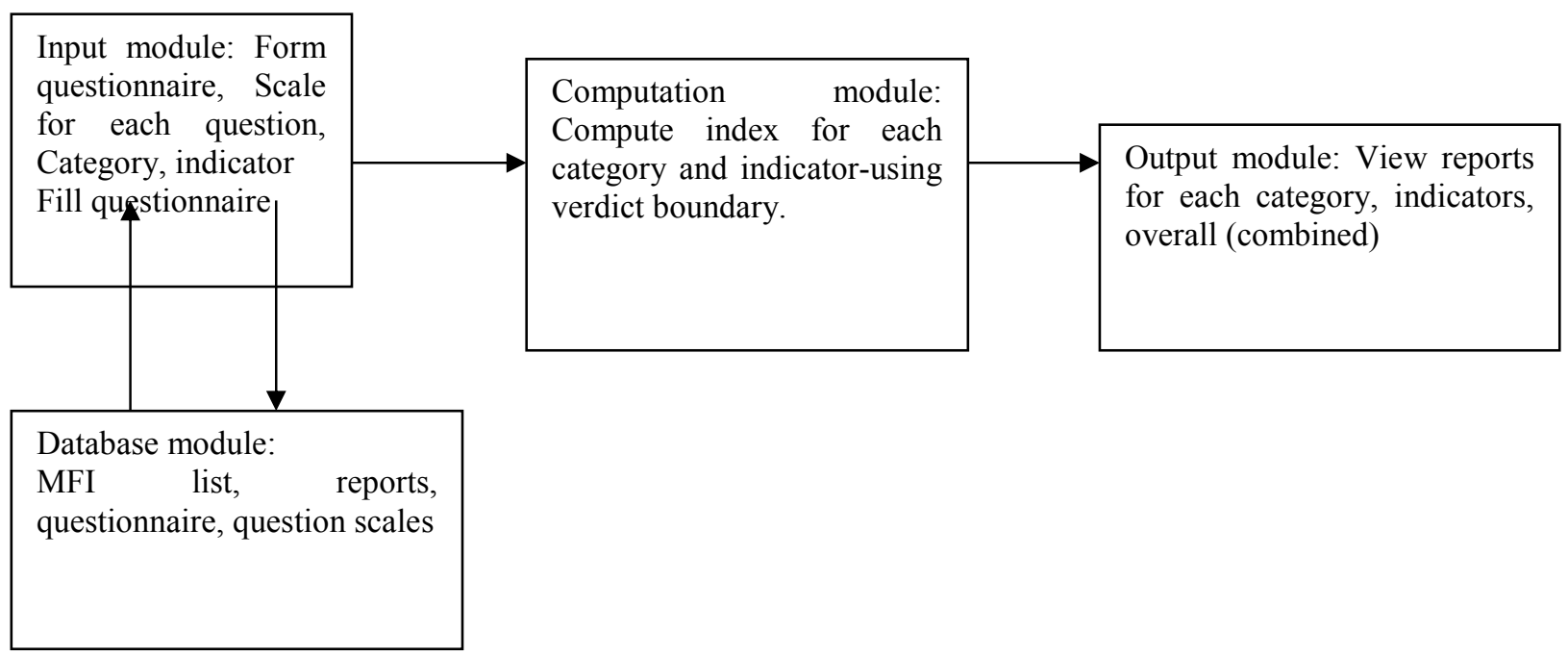

Figure 2. Information system architecture

In the Input module, the system administrator's deals with adding categories, adding indicators, adding questions. After this, the admin can then form a questionnaire. For a person to carry out all these duties he/she must first login and this authenticated User performs two steps in this stage and one step in the output module. Step 1 includes login to the system by providing a username and password. One is supposed to be registered to do this. This is for the purposes of record keeping. Hence, new users are first asked to register the institution, after which they can then proceed to login. Step 2 involves answering the questions. The condition in this step is that all questions must answer. The user then clicks the 'submit' at the end of the questionnaire so as to move to the next step in output module. Each question has options with unique values as shown below;

Strongly disagree $\quad 1$

Disagree 2

Neutral 3

Agree 4

Strongly agree $\quad 5$

Every question belongs to an indicator, which then belong to a category.

In the Computation/processing module responses to questions as entered by the user are grouped under indicators and/or categories and the average value calculated. Depending on the average value, a light is shown as illustrated in table 1 i.e.

If the value is between 0 and 2.5 , color Red is displayed

If the value is between 2.5 and 3.5 , amber is displayed

If the value is between 3.5 and 5 , green is displayed

The colors are symbolic of the level of E-readiness i.e.

Red means alot has to be done to achieve e-readiness

Output modules display reports of the processed questions. User can the view reports submitted. Results can be in the form of $2 \mathrm{D}$ bar charts, 3D bar charts, $2 \mathrm{D}$ pie charts, curves and $2 \mathrm{D}$ doughnut. The database stores the reports as well as incomplete assessment entry. For reports to be displayed the condition of minimum five entries/submission must be achieved in the questionnaire. A user cannot carry out more than one submission because of the authentication process in one assessment. Database design of the e-Readiness website is inform of database shema. It shows the various tables of the system and the relationships between them. It shows the various tables of the system and the relationships between them.

\subsection{System Requirements}

This information system can be hosted by any ISP. The users of the system require to have Mozilla Firefox browser version 3.5.1 or higher or Windows ${ }^{\circledR}$ Internet Explorer version 7.0 or higher to display the web pages properly. 


\subsubsection{End user manual}

For effective use of this information system, a user manual has been developed, to assist the user to exploit all the features of the system. Once the user visits the website, the home page appears.

\subsubsection{Home page}

The home page contains a brief introduction to the use of the site as shown in fig.6. The home gives the user an option of logging into the site if they are already registered or register themselves with details that they will use in future visits.

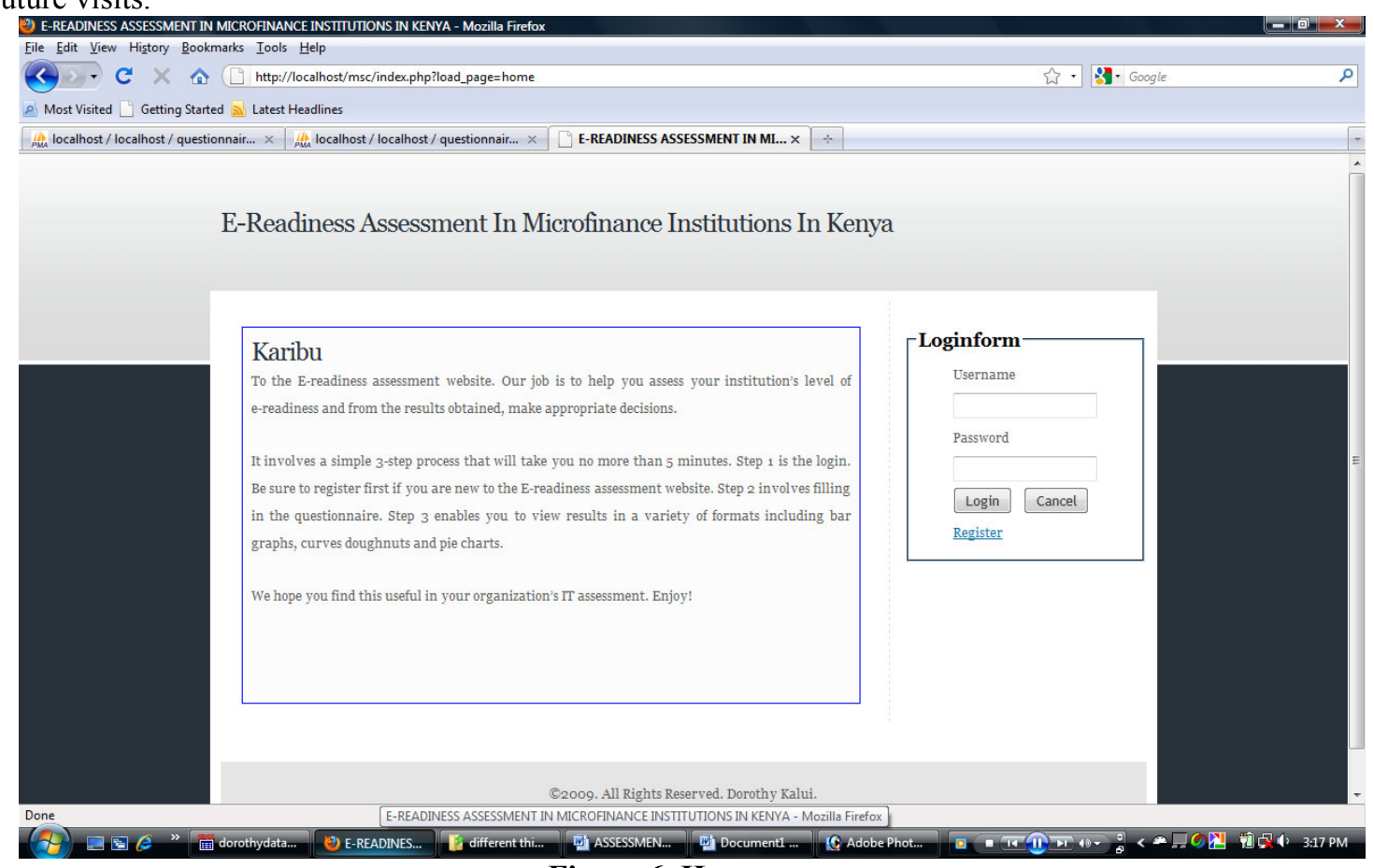

Figure 6. Home page

\subsubsection{Login form}

If the user is a regular user, they will be required to supplier their user name and password in the login form, then click on the login tab shown in fig.7.

\subsubsection{Registration form}

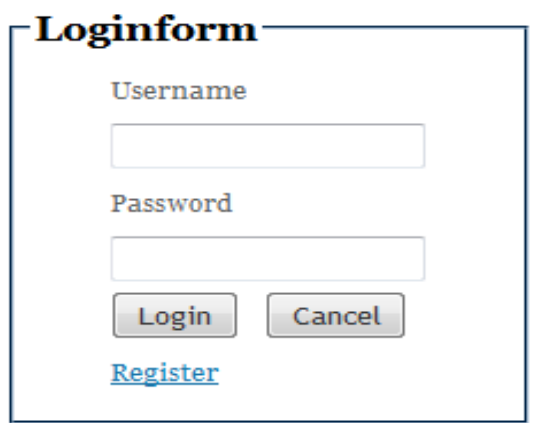

Figure 7. Login form

A new visitor to the site will be required to register first in fig. 8 . To do this, they will be required to click on the Register hyperlink in the login form. This will open the following window, to allow a user to supply the name of the institution, username and password and then submit the form.

Upon submission, the user will see a dialog informing then whether the registration was successful or not. If the registration is successful, the user can then login using the login form. This will take the user to the questionnaire form. 


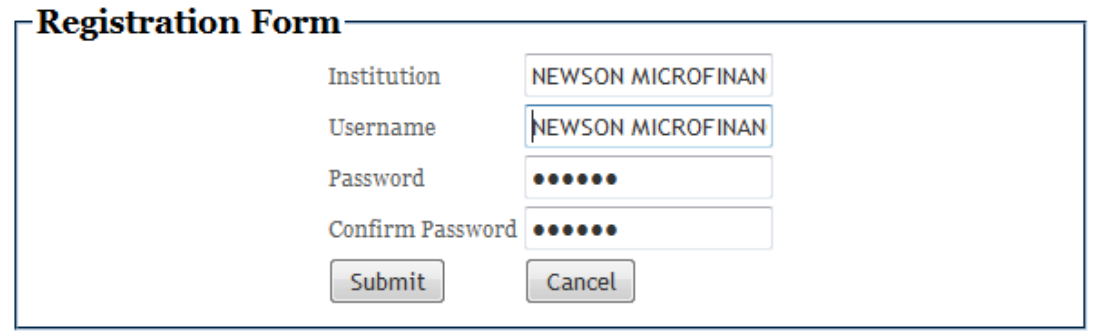

Figure 5. Registration form

\subsubsection{E-readiness assessment questionnaire/statements}

The questionnaire form consists of thirteen questions as shown in fig.9. The answers to these questions are perceptive and are picked from a drop down menu in the column called responses. To select a response, the user clicks on the downward arrow of the tab in the response column corresponding to the question in the questions column. Once all the questions have been responded to, the user then submits the questionnaire by clicking on the submit tab.

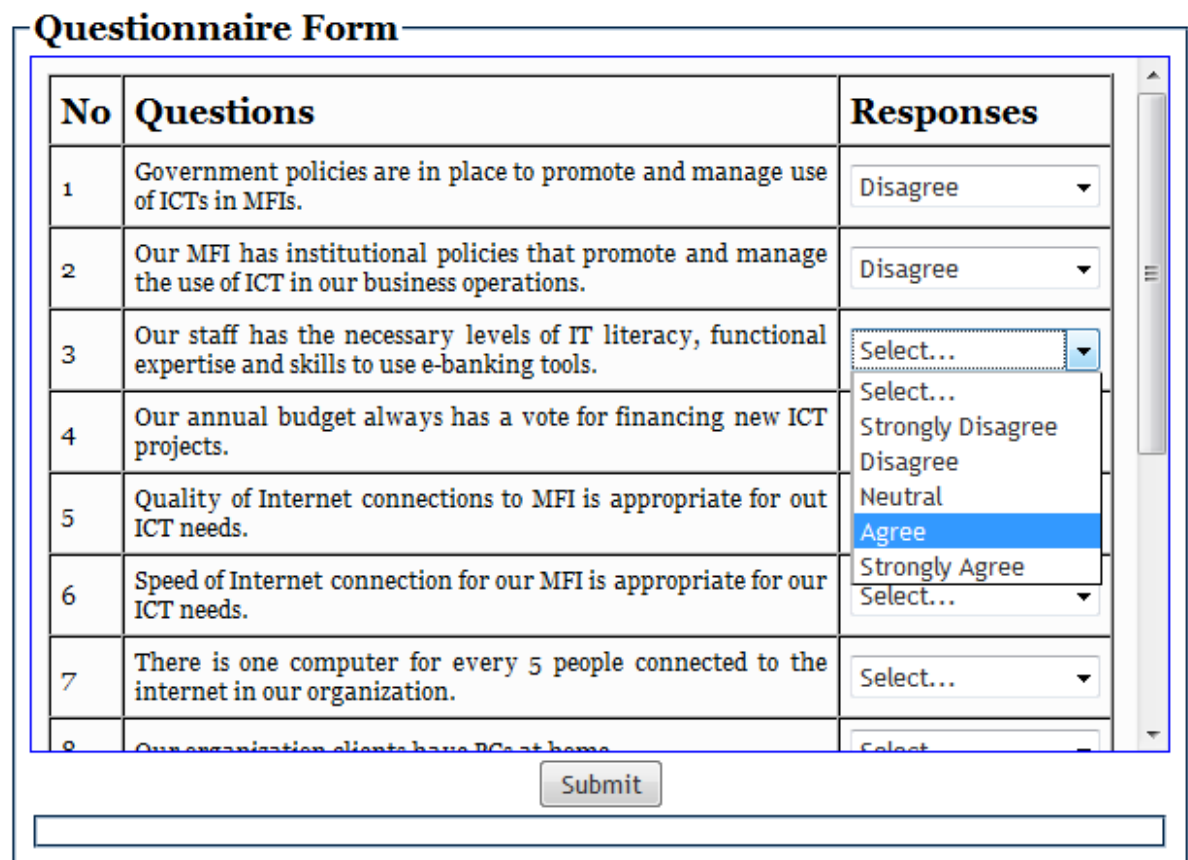

\subsubsection{Results in categories}

Figure 6.Questionnaire

If the form is successfully submitted, the data supplied is analyzed and results of the state of E-Readiness per category are displayed in a table with three columns. The first column is the category column, the second column displays the staging using three types of blinking lights which indicate the stage of a particular category in eReadiness. The third column has the explanation to explain the meaning of the stage indicated against a category. To view the stage of the indicators under a particular a category, the user should click on the name of the category shown in fig. 10 . 


$\left(\begin{array}{|l|l|l|}\hline \text { Results } & \text { Stage } & \text { Expalanation } \\ \hline \text { Network policy } & & \text { E-Ready } \\ \hline \text { Network Access } & & \begin{array}{l}\text { Attention Reguired to } \\ \text { achieve E-Readiness }\end{array} \\ \hline \text { Networked Society } & & \begin{array}{l}\text { Urgent attention } \\ \text { Reguired to achieve } \\ \text { E-Readiness }\end{array} \\ \hline \text { Networked Economy } & & \begin{array}{l}\text { Urgent attention } \\ \text { Reguired to achieve } \\ \text { E-Readiness }\end{array} \\ \hline\end{array}\right.$

\subsubsection{Results indicators}

Figure 7. Example of e-readiness of categories

If the user clicks the Networked Society for example, the following fig. 11 will show again with blinking colours indicating the individual state of the indicators with an explanation against it.

\begin{tabular}{|l|l|l|}
\hline Nesults & Stage & Expalanation \\
\hline ICT in Everyday Life & & $\begin{array}{l}\text { Attention Reguired to } \\
\text { achieve E-Readiness }\end{array}$ \\
\hline Clients and MFIs online & & $\begin{array}{l}\text { Urgent attention } \\
\text { Reguired to achieve } \\
\text { E-Readiness }\end{array}$ \\
\hline ICT in MFIs(workplace) & & $\begin{array}{l}\text { Urgent attention } \\
\text { Reguired to achieve } \\
\text { E-Readiness }\end{array}$ \\
\hline Back & & \\
\hline
\end{tabular}

Figure 8. Example of e-readiness of indicators

\subsection{Administrator manual}

It is also important to provide the administrator manual for the system administrator.

4.3.1Administrator login form

The administrator's login form appears upon uploading the administrator's page. The administrator will be required to enter username and password as indicated in fig. 12.

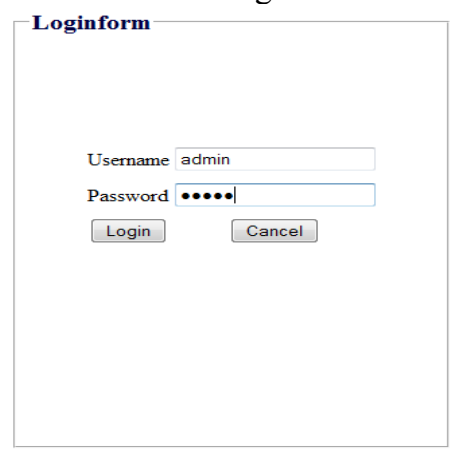

4.3.2 Category editing form

Figure 9. Illustrating administrator's login form

Upon successful login, the category editing form appears shown in fig.13. From this environment, the administrator can add, update or delete a category. Using the tab at the top of the form, one can pick on any other editing forms. 


\section{E-Readiness Assessment In Microfinance Institutions In Kenya}

\section{QUESTION CATEGORY | INDICATOR | QUESTION | INSTTTUTIONS | VERDICT BOUNDARIES | USERS}

\section{Category Form}

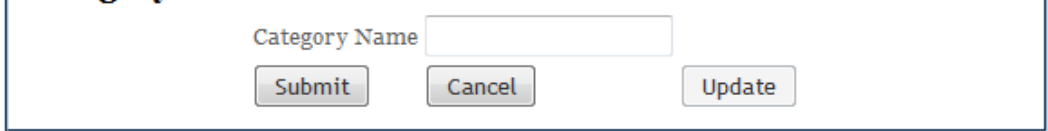

Quick Links

Category Information

\begin{tabular}{|l|l|l|l|}
\hline Id & Category Name & Update \\
\hline 20 & Network policy & Edit & Delete \\
\hline 21 & Network Access & Edit & Delete \\
\hline 22 & Networked Society & Edit & Delete \\
\hline 23 & Networked Economy & Edit & Delete \\
\hline
\end{tabular}

\subsubsection{Indicators editing form}

Figure10. Illustrating category editing form

Clicking on the indicator tab will allow the administrator to add, update or delete an indicator of a particular category. An indicator can only be added on to an existing category as indicated in fig. 14 .

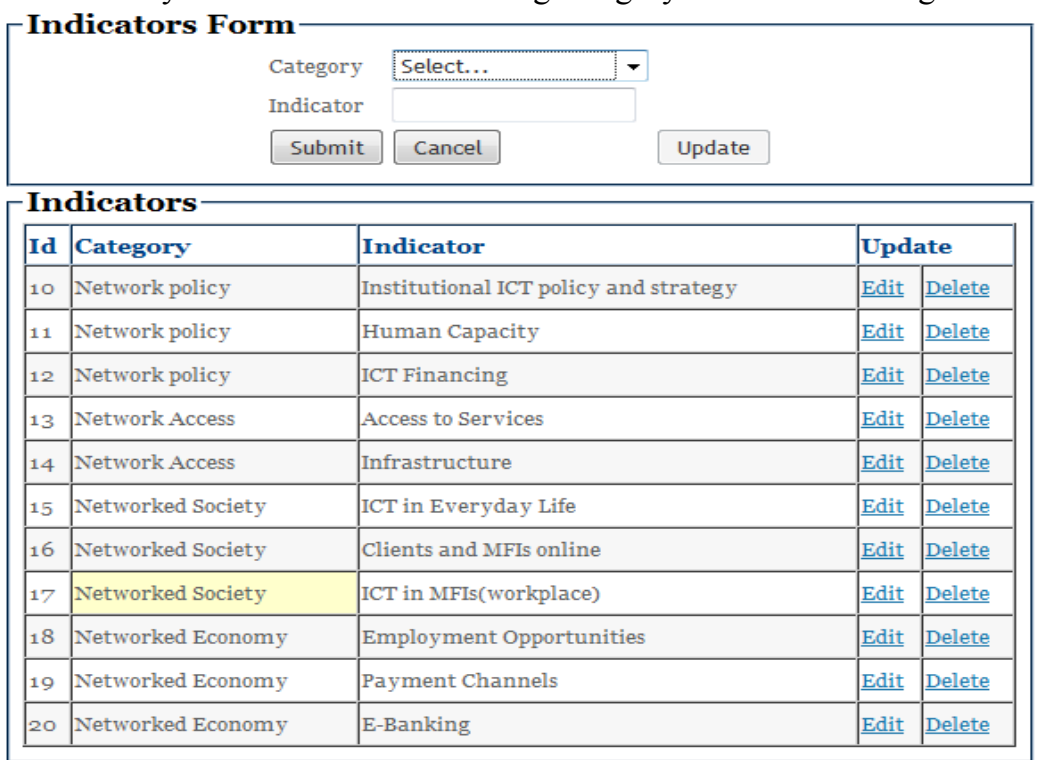

\subsubsection{Questions editing form}

Figure11. Example of indicators editing form

On clicking on the question tab, the form for editing the questions in the question is downloaded. A question can only be added to an existing indicator as shown in fig.15. Further, the administrator can delete or update an existing question. 


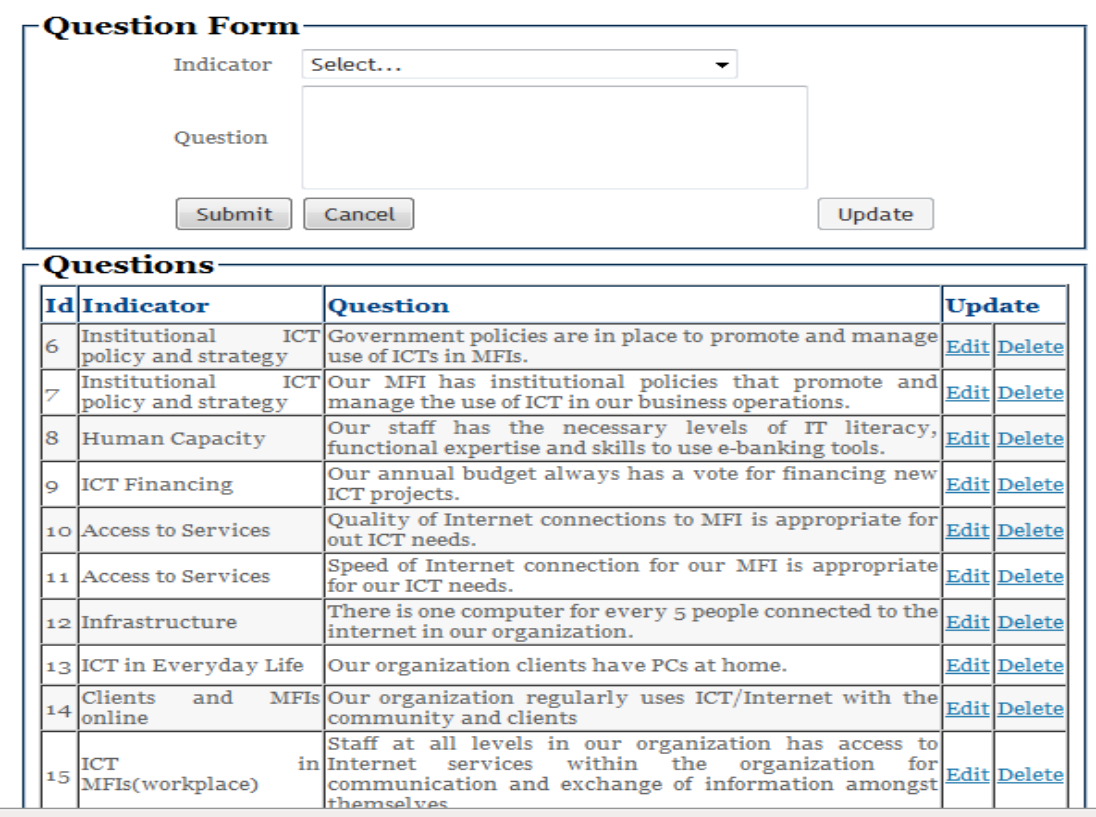

4.3.5 MFIs editing table

Figure12. Example of questions editing form

On clicking on the institution tab in fig.16, the listing of all the registered MFIs is displayed.

\begin{tabular}{|c|c|c|c|c|c|}
\hline Id & Institution Name & Username & Password & Upd & late \\
\hline 10 & MFI5 & kale & kale & Edit & Delete \\
\hline 16 & MFI6 & mercy & mercy & Edit & Delete \\
\hline 18 & MFI8 & Sham & sham & Edit & Delete \\
\hline 19 & mfi5 & mfi5 & mfi5 & Edit & Delete \\
\hline 20 & mfi1 & mfi1 & mfi1 & Edit & Delete \\
\hline 21 & $\operatorname{mfi} 2$ & mfi2 & mfi2 & Edit & Delete \\
\hline 22 & mfi3 & mfi3 & mfi3 & Edit & Delete \\
\hline 23 & mfi4 & mfi4 & mfi4 & Edit & Delete \\
\hline 24 & mfi1 & mfi1 & mfi1 & Edit & Delete \\
\hline 25 & jack & jack & jack & Edit & Delete \\
\hline 26 & NEWSON MICROFINANCE & NEWSON MICROFINANCE & newson & Edit & Delete \\
\hline
\end{tabular}

Figure13. Illustrating Mfi's editing table

\subsubsection{Boundary editing form}

When the admin clicks on the verdict form, then a form for adding extra boundaries for analysis appears. The admin can add, or make any other changes as necessary shown in fig. 17. 


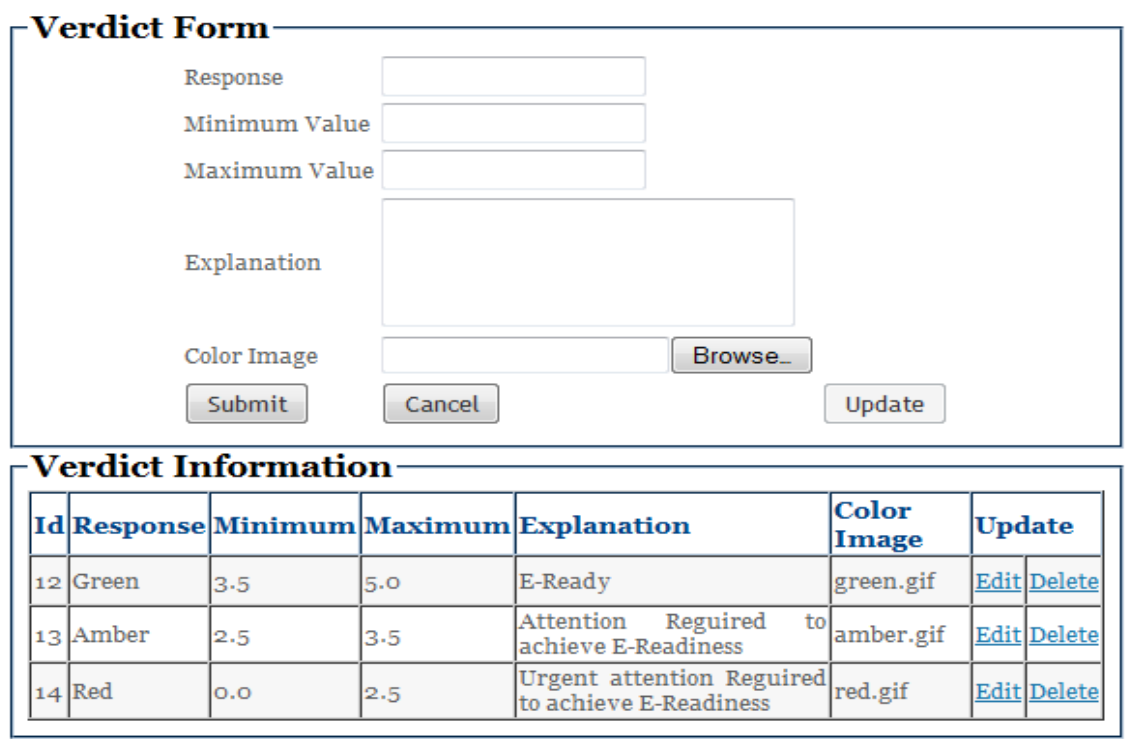

Figure14. Example of Boundary editing form

4.3.7 Administrator name and password editing form

The administrator can also add other administrators to the system with whom to share responsibilities using the user form shown in fig. 18 .

\begin{tabular}{|c|c|c|c|c|c|}
\hline \multicolumn{6}{|c|}{-User Form - } \\
\hline & & Username & & & \\
\hline & & Password & & & \\
\hline & & Confirm Password & & & \\
\hline & & Submit & Cancel & Update & \\
\hline Us & & & & & \\
\hline Id & Username & & Password & Update & \\
\hline o & & & & Delete & Update \\
\hline 1 & admin & & admin & Delete & Update \\
\hline
\end{tabular}

Figure 15. Example of administrator name and password editing form

\section{Conclusion}

We presented information System for carrying out E-Readiness assessment for Kenyan MFIs which is scalable and easy to use. Our information system implementation and extensive evaluation under various realistic scenarios demonstrate its resilience and practicality. Towards the future we can incorporate MFIs clients ereadiness assessment module.

\section{REFERENCES}

Al-Fahim, N. H. (2012). Factors Affecting the Adoption of Internet Banking Amongst IIUM' students: A Structural Equation Modeling Approach (SEM). Journal of Internet Banking and Commerce, 17(3).

Aminali, P., Albadvi, A., \& Naude, P. (2009). Application of VERDICT for Electronic ReadinessAssessment within Iran's Automotive Industry, (October 2007).

APEC. (2000). The Asian Pacific Economic Co-operation.

Auta, E. M. (2010). E-Banking in developing economy: empirical evidence from Nigeria. Journal of Applied Quantitative Methods, 5, 212-222.

CBK. (2013). Central Bank of KenyaBank supervision annual report for microfinance institutions in Kenya.

CBK. (2014). Bank supervision annual report for microfinance institutions in Kenya.

Chavan, J. (2013). Internet banking- benefits and challenges in an emerging economy, 1(1), 19-26.

CID. (2001). Centre for International Development. Havard. Retrieved from www.readinessguide.org

CSPP. (1998). E-Readiness Guide For Living in the Network World . 
Gbadeyan, R. ., \& Gbonda, O. o. . (2011). Customers' preference for e - banking services : a case study of selected banks in Sierra leone. Australian Journal of Business and Management Research, 1(4), $108-116$.

Geoffrey R. Marczyk, David DeMatteo, D. F. (2005). Essentials of Research Design and Methodology. 2005. New Jersey.: John Wiley \& Sons.

Kothari, C. R. (2008). Research Methodology: Methods and Techniques. (N. DelhiIndia, Ed.) (2nd Ed). : New Age International Publishers.

Kumar, A., Nair, A., Parsons, A., \& Urdapilleta, E. (2006). Expanding Bank Outreach Through Retail Partnership:Correspondent Banking in Brazil. World Bank Working Paper No. 85.

Makosana, M. (2014). Customers'adoption of electronic banking: An investigation on the commercial banking industry in Zimbabwe. International Journal of Economics. Commerce and Management United Kingdom, 2(7), 1-13. https://doi.org/10.2139/ssrn.2466413

Masocha, R., Chiliya, N., \& Zindiye, S. (2011). E Banking adoption by customers in the rural milleus of South Africa: A Case of Alice, Eastern Cape, South Africa. African Journal of Business Management, 5(5), $1857-1863$.

McConnell. (2001). Risk E-Business: Seizing the Opportunity of Global E-Readiness.

Mulwa, M., \& Waema, T. (2016). Understanding Mobile Banking from a Theoretical Lens: Case Studies of Selected Kenyan M-Banking Products. . International Journal of Innovation in the Digital Economy, 7(1), 54-68. https://doi.org/doi:10.4018/IJIDE.2016010105

Mwongeli, D., \& Christopher, K. (2015). E-Readiness assessment of microfinance institutions in Kenya, 5(10), 61-80.

Mwongeli, D., Moturi, C., \& Muketha, G. (2017). An Investigation into Customers' Requirements for Electronic Banking: A Case Study of Microfinance Institutions (MFIs) in Kenya, 8(2), 30-33. https://doi.org/10.4018/IJIDE.2017040104

Ozuru, H. N., Chikwe, J. E., \& Uduma, I. (2010). The use of traditional payments and electronic payments in Nigeria. In Proceedings of the 11th Annual Conference of International Academy of African Business and Development.

Padaachi, K., \& Seetanah, B. (2010). A study on the use of Internet Banking among SMEs Mauritius. In International Research Symposium in Service Management. (pp. 198-205). Knopf Doubleday Publishing Group, USA. https://doi.org/ISBN 9780385503860

Pallat, J. (2003). A Step by Step Guide to Data Analysis Using SPSS, 229-240.

Peters, T. (2001). Comparison for E-Readiness Assessment Models. Retrieved from http://www.bridges.org

Ruikar, K. (2004). Business process implications of e-commerce in construction organizations.

Susantya, A., Handayanib, N., \& Henrawanc, M. Y. (2012). Key Success Factors that Influence Knowledge Transfer Effectiveness: A Case Study of Garment Sentra at Kabupaten Sragen. In Proceedings of the International Conference on Small and Medium Enterprises Development with a Theme. https://doi.org/doi:10.1016/S2212-5671(12)00317-6

Walterfield, C., \& Ramsing, N. (2004). Management Information Systems for Microfinance Institution, a Handbook. 